\title{
O SENTIDO DA DIPLOMACIA E DOS FLUXOS COMUNICACIONAIS NESTE INÍCIO DE TERCEIRO MILÉNIO
}

\section{Marco António Baptista Martins* Pedro Simões**}

\begin{abstract}
RESUMO
O presente artigo, numa perspectiva das ciências sociais, concretamente das relações internacionais, pretende demonstrar como a diplomacia se encontra interligada com os fluxos comunicacionais de uma sociedade cada vez mais interdependente, num mundo tendencialmente globalizante.
\end{abstract}

\section{PALAVRAS CHAVES}

Diplomacia, comunicação, globalização, segurança, diplomacia pública.

\begin{abstract} world.

\section{KEY WORDS}

Diplomacy, communication, globalization, security, public diplomacy
\end{abstract}

This paper, in terms of Social Science, as International Relations, pretends to analyze how diplomacy is connected as a network structure in a society more independent, in a globalised

\section{APONTAMENTO AXIOMÁTICO}

Neste início de "terceiro milénio", o sistema internacional post-11 de Setembro, em que um território até àquele preciso momento considerado de invulnerável assistira, via $C N N$, ao desaparecimento, no coração de Manhattan, das duas torres gémeas, símbolos por excelência de poder hegemónico norte-americano com vista para o Atlântico, vem acelerar a movimentação em torno da chamada sociedade civil, alterando, consequentemente, o próprio conceito espácio-temporal da actuação da diplomacia, na sua acepção clássica, na arena internacional, enquanto instrumento pacífico da política externa.

\footnotetext{
* Mestre e Doutorando em Relações Internacionais pelo Instituto Superior de Ciências Sociais e Politica, da Universidade Técnica de Lisboa.

** Doutor em Ciências da Informação (Universidad San Pablo CEU/Madrid); Mestre em Ciencias da Comunicação (UFP(Porto).
} 
O reforço da sociedade civil tem vindo a ser acompanhada paralelamente quer por uma complexidade crescente no processo de edificação da network structure, cujo epicentro se circunscreve numa espécie de "sub-mundialização" à escala doméstica de cada Estado (entidade soberana) quer pela incapacidade da elite governante em dar resposta face à velocidade comunicacional dos fluxos de informação entre os estados (actores das relações internacionais), nomeadamente emanados da respectiva utilização por aqueles "povos mudos" considerados ao olhar do Ocidente como tendo todo um sistema errado desde a componente governativa à sociedade, apesar do esforço por parte da Organização das Nações Unidas em contrariar essa postura, a fim de "entregar", de devolver a voz a esses povos.

Contudo, a partir da Queda do Muro de Berlim (09 de Novembro de 1989), da implosão da União Soviética (25 de Dezembro de 1991), e sobretudo dos ataques efectuados pelos "poderes erráticos" naquele dia fatídico 11 de Setembro de 2001, a guerra no Iraque (2003) e os atentados em Madrid (11 de Março de 2004), os povos mudos, com a lição sobejamente aprendida, procederam a uma transformação inegável do ponto de vista conjuntural da sociedade ao nível mundial em que através da network structure deixaram de existir lugares intangíveis neste "caminho para a unidade virtual do mundo de resistência assimétrica", tendencialmente globalizante na esfera económico-financeira.

Por conseguinte, o "caminho para a virtualidade da unidade do mundo", não é mais do que o caminho para a cyborgisation, ${ }^{1}$ em que o próprio Estado possa ser comparado a um cyborg por conectar a Humanidade numa network structure, a fim de lhe ser retirada, de forma aparente, os valores concernentes ao sentido epistemológico de Identidade Ocidental.

Daí que, a prática da diplomacia tradicional tal como a conhecemos, vai para além da evolução teórica, situando-se cada vez mais em termos práticos e concretos num mundo inconstante de caminho incerto, com regimes antagónicos de convergências pontuais e imprevisíveis que levam à emergência de outras formas de diplomacia, de outros actores regionais visíveis/formais, invisíveis/informais nas relações internacionais num esforço de manutenção de um equilíbrio entre o lícito (estruturas oficiais e institucionais) e o ilícito (poderes erráticos) em que o tempo medido se apresenta a duas velocidades sobrepostas, citando o Prof. Doutor Adriano Moreira a que qualifica como a "espuma dos tempos".

\section{AFORISMO TEMPORAL E CIBERNÉTICA}

É neste contexto, que se deve observar o sistema internacional e a evolução da diplomacia como se de um túnel do tempo se tratasse, com breves segundos de imobilidade, tendo presente a recordação do impacto dos aviões nas Torres Gémeas. Esses breves segundos, essa fracção, constituíram por si só uma eternidade no 
interior da consciência daqueles que ali perderam a vida, levando a questionar o sentido do tempo. São o passado, o presente, o futuro, uma mera linha contínua por onde a Humanidade caminha, onde vive e morre?

Nesse instante, através do pensamento inconsciente aclamando de viva voz e de solidariedade ao assistir via $C N N$, assumindo a identidade norte-americana, congelando assim o fluxo contínuo dos segundos a sucederem-se. É isso o presente, aquilo que vemos, ouvimos e tocamos neste sistema internacional post-11 de Setembro? Que forma de diplomacia a utilizar para responder ao desconhecido? A realidade leva-nos a observar e a tocar cada fracção de segundos vividos no presente, no tempo real, como um instante considerado de estático, violando o princípio da sua mobilidade, da sua mudança, por outras palavras a continuidade do tempo. Este princípio é indefinido quando estamos a vivê-lo. Aliás, "o tempo revela-se, para além da sua dimensão de constante analítica, como referência de regulação permanente da acção humana. Entre outras manifestações, essa referência encontra expressão concreta, em termos de função regulatória, numa prática justificadora, consensualizada, da celebração cíclica dos factos ou dos momentos históricos, considerados como marcos decisivos para a construção e preservação da memória colectiva do grupo, no processo evolutivo e complexificador dos fenómenos culturais e societais." (Santos, 2002: 129).

Num momento específico, esse instante transforma-se, segundo os nossos sentidos, pela acção a executar. A relação entre a consciência do tempo e o intervalo inconsciente da observação permitiu que a acção mental determinasse a observação de um túnel, vindo preencher a abstracção espácio-temporal sentida até àquele instante, do impacto à aplicação do hard power em território iraquiano, levando à demissão de Ronald Rumsfeld, por pressão profetizada pela opinião pública em forma de input na Casa Branca. O tempo ficou preenchido como uma função regulatória.

Fugindo ao espírito geométrico de Pascal, passamos do presente ao passado ao recordar a não aplicabilidade do soft power e da consulta da sociedade dita de civil, interrogando-nos concernente à sua função, no sentido de nos enviar para uma sucessão de memórias de instantes vividos exponencialmente derivado da velocidade cibernética.

O tempo não é algo que exista por si só. Somos nós que o concebemos com a nossa intuição, recordação, memória, do nosso estado interior, rodeados pelo nosso espaço exterior. A determinação de cada estado, na qualidade de actor das relações internacionais, provoca a predisposição do movimento do objecto, neste caso concreto da diplomacia a exercer. $\mathrm{O}$ tempo não se alterou, permaneceu idêntico, o que mudou foi a sua unidade na consciência individual ao culminar de um somatório de consciências colectivas via network. Interpretaríamos tal encontro como uma translação (translatio) ou alteração (alteratio, -onis) do tempo, unindo e formando movimento com simultaneidade. 
Por conseguinte, numa óptica santo augustiniana, o efeito vem explicar que não existiria passado sem acontecimento, e não existiria futuro sem presente, como uma continuidade da nossa própria consciência de todos os movimentos reais. Ao tentar analisar o tempo, estamos a provocar propositadamente que o deixe de ser pela sua divisibilidade infinita. Contudo, existe a possibilidade de parar o tempo utilizando a sua projecção ilusória da eternidade. A percepção de um túnel da tal network structure leva à questão da vida e da morte, da lei natural da nossa passagem num determinado lapso de tempo. Esta incondicionalidade da vida, da realidade humana na sua mortalidade, encontra-se na especificidade da multiplicação de actores na arena internacional.

O túnel, interpretado como a ansiedade de chegar ao seu fim, à essa luz desejada e temida, na realidade traduz-se na vontade de mudar, da passagem para uma outra dimensão na fase da vida de cada Estado (entidade soberana), desenhando novas fronteiras, tal como "na passagem para o ano 2000, teve início um novo milénio para a humanidade, o qual ocorreu não de um forma global, no seu significado simbólico, mas sim segmentada, em função dos graus de desenvolvimento ou atraso de cada país, de cada região. Enquanto alguns países ou regiões se encontram já em pleno séc. XXI, sendo capazes de criar novas formas de vida e de convivência, com uma concepção da sociedade mais ampla, global, complexa e dinâmica, outros lutam por abandonar um ambiente mais conservador e retrógrado, e outros ainda por renunciar a uma situação que os coloca em condições de vida e padrões de pensamento, que foram mote do séc. XIX." (Marchueta, 2002: $174)$.

Justamente, modificar o tempo é mudar a vida, provocando o surgimento de um novo actor, proveniente da sociedade dita de civil, os info-excluídos, e alargando a distância entre os info-ricos e os info-pobres. Estes últimos, constituem, simultaneamente e indirectamente, a força imediata da mudança e a determinação de sentir o avanço do tempo, desse túnel na acção humana. Caso o Homem pretenda seguir a natureza e aceitando tal qual o sistema com todas as suas propriedades, falamos de oposição ao espírito, à liberdade e à personalidade.

Conquanto, na situação de intervenção humana, entramos no domínio da acção, da irracionalidade versus racionalidade, da imoralidade versus moralidade, tendo por fim a mudança da natureza em si que resulta da vontade espontânea humana para efectuar uma transmutação dos elementos e da matéria que o rodeiam, traduzidos na defesa do interesse nacional e da execução da política externa, dependendo mais da capacidade do que da própria vontade, e por vezes congregando constelações de sub-sistemas de actores regionais para bloquear ou exercer a sua influência, contrariando a tendência unipolar de o todo-poderoso, como é referido por Madeleine Albright, actual Presidente do National Democratic Institute for International Affairs. Neste sentido, Madeleine Albright considera o seguinte: "em 2001, ao deixar o Governo, regressei a um amor antigo -as salas de aula da Universidade. Em Georgetown, dou um curso por semestre, alternando 
entre os alunos de pós-graduação e os de licenciatura. No início de cada curso explico aos meus estudantes que o principal objectivo da política externa é o de persuadir os outros países a fazerem aquilo que nós queremos. Para esse fim, um presidente ou secretário de Estado tem ao seu alcance uma série de ferramentas que vão desde a força militar bruta até ao árduo trabalho de negociar, passando pela simples argumentação lógica." (Albright, 2006: 29).

Não se trata de teologia, de espírito metafísico, de estado positivo (no sentido da procura de leis da natureza), mas sim da própria concepção da complexidade crescente actual de cada um dos $\mathrm{Eu}(\mathrm{s})$ formados por essa Humanidade e Desumanidade vivida sem fronteiras, sem previdência resultante da ciência, em torno de uma superpotência na procura do exercício hegemónico. Este último, resulta da conjugação do hard power com o soft power ${ }^{2}$ em nome do combate ao terrorismo na tentativa de conservar o sistema (homeostática) num processo em que o surgimento de novos actores com lugares tangíveis têm vindo a auto-transformar o mesmo (homeoresis) na procura do equilíbrio (homeostase) por parte dos "povos mudos" de uma ordem bipolar constituída pela dupla NATO / Pacto de Varsóvia para uma ordem composta por sistemas e sub-sistemas cibernéticos virtuais interligados por cabos de fibras ópticas cujo interesse nacional se baseia, por um lado, na concretização de relacionamentos intrasistémicos ${ }^{3}$ de alianças e parcerias pontuais e, por outro lado, na fusão de grandes grupos económicos que procuram uma mão-de-obra barata. Por outras palavras como sublinha Chris Hables Gray: "We need to practice cyborg family values: good maintenance, technical expertise, pleasures dispersed and multiple, community research and development, improved communication. We need to be cyborg citizens: embodied, connected, and committed." (Gray, 2005: 151).

O sofrimento não parte de uma ciência mas de ciências, começando pelo Homem, enquanto ser por vezes sem ser (info-excluídos), em que teletransporta a sua dor para outrem, em forma de rede interligada para cada um dos núcleos dos átomos e de sua energia, provocando a abertura desse caminho para o choque de civilizações defendido por Huntington. ${ }^{4}$

Acrescentaríamos com um cyberactivism e hacktivism cada vez mais acentuados e eficazes, infectando e subvertendo a rede cibernética. Vejamos os casos www.worldbunk.org ou www.whirledbank.org que refere: "Our Dream is a World Full of Poverty." (McCaughey; Ayers, 2003).

A Internet é utilizada como veículo de formação social, de comunicação, de educação, de mobilização ideológica, religiosa e também como uma via para partilhar os recursos logísticos dos ciberactivistas, derrubando as fronteiras tradicionais e transformando a informação em desinformação como um circuito web de plataforma propagandista.

A diplomacia também faz parte desse mundo, sob a forma e-diplomacy, a partir do momento em que cyberactivism e hacktivism estabeleçam uma network structure de milhões de hyperlinks na defesa de uma causa contra um determinado 
Estado, negociação em organizações internacionais, e em reuniões como Davos, delineando uma nova teoria dos jogos em que os vencedores e vencidos podem perecer no campo de batalha virtual ou não.

\section{DA DIPLOMACIA À SOCIEDADE CIVIL DE TENDÊNCIA GLOBAL}

Neste âmbito, concernente à questão da complexidade crescente, iniciada pelo Padre Telhard de Chardin no Fenómeno Humano e desenvolvida pelo Prof. Doutor Adriano Moreira, ampliaríamos à implicação da noção de continuidade e descontinuidade ao tentar diferenciar o real do irreal, e de igual forma das distintas conexões de rede que se vão verificando, dessa espécie de sentimento de dualidade e posteriormente de cumplicidade cibernética, como o surgimento da chamada $e$ diplomacy, no meio extra-diplomático (entenda-se corpo não diplomático), em consequência paralela projectada para o exterior da conceptualização de diplomacia pura, tal como é clarificada pelo Embaixador José Calvet de Magalhães: "Com este último elemento se completa a análise do conceito de diplomacia que, quanto a nós, se define do seguinte modo: (a) um instrumento da política externa, (b) para o estabelecimento e desenvolvimento dos contactos pacíficos entre os governos de diferentes Estados, (c) pelo emprego de intermediários, (d) mutuamente reconhecidos pelas respectivas partes. A estes intermediários se chama agentes diplomáticos. Á diplomacia assim entendida chamamos diplomacia pura para distinguir de todas as outras acepções em que a palavra diplomacia é frequentemente empregada, e nas quais entram por vezes elementos que nada têm a ver com a actividade diplomática ou, pelo contrário, pecam por lhes faltarem algum ou alguns dos elementos essenciais que deixámos referidos." (Magalhães, 1995: 90).

Por vezes, vemos como é complexa a explicação de uma complexidade crescente, porém não deixa de ser real, e, simultaneamente, irreal na concepção da virtualidade com os seus princípios de incerteza perante essa aldeia global, integrando a chamada sociedade civil de tendência global, enquanto possível futuro novo actor: "The social reality of GCS includes important agents, relevant factors, distinctive system dynamics and processes, inducing significant structural changes in the relational environment. To considerer the GCS as a global actor, however, is yet another epistemological misnomer, an intellectually misleading gadget serving as a problem-solving theoretical by-product of both neorealism and neoliberalism. At the same time, its politically biased potential, turns the concept into an instrumental rationalist tool derived from the "neo-neo" consensus, rather then from the inherent theoretical debate, and strategically conceived to sustain and promote the traditionally dominant stance of positivist approaches in I.R.theory." (Santos, (Primavera 2006): 175)

O processo em curso da globalização nem pode nem deve ser considerado e inserido numa perspectiva ocidental. Trata-se, sim, da inclusão de famílias, de grupos, de sub-regiões, de regiões cujos comportamentos social, cultural, político e 
económico detenham uma particular similaridade e defesa do interesse nacional em termos de uma nova agenda internacional, no combate ao crime organizado e ao terrorismo, nas questões ambientais, nas transacções financeiras, na saúde, na migração, no acesso, formação e divulgação das novas tecnologias. Justamente, o surgimento desses novos actores que têm vindo a utilizar e a acompanhar na década post-queda do Muro de Berlim, a extensão de sistemas e vias de comunicação, desde o tradicional correio, aos transportes aéreos, terrestres e marítimos ao mundo cibernético, interligando por exemplo Tóquio à Cidade do Cabo, sem sequer ter a necessidade de deslocação in loco.

O mesmo tem vindo a ocorrer com o número crescente de utilizadores dos videojogos como a Playstation ou a $X$-Box via on-line. Esses utilizadores, num quarto, numa garagem não só jogam como também se envolvem virtualmente numa espécie de intercâmbio de informação entre o país A (Cabo Verde), B (Tunísia) C (Rússia) D (Alemanha) E (Perú) F (Estados Unidos) em que se encontram a viver. $\mathrm{O}$ resultado desse diálogo qualquer que seja o objectivo em mente, é também diplomacia.

De facto, toda a consequência emanada deste longo processo de globalização e de mundialização provoca uma alteração significativa dos padrões educativos, sociais, culturais, demográficos, económicos e financeiros, resultando assim numa maior interdependência da teia de redes entre as sociedades civis com tendência a transformar-se numa sociedade civil global enquanto novo actor das relações internacionais e instrumento/ arma estratégica quer de soft power quer de hard power na concretização e defesa do interesse nacional de cada estado.

Daí que se estejam a desenhar novos tipos de política transnacional, social, cultura com uma dinâmica e velocidade de actuação em tempos reais. As consequências na esfera doméstica, como o caso da diplomacia tradicional, em que é exigido aos próprios agentes diplomáticos um nível de conhecimentos especializados para que saibam filtrar a aglomeração da informação e dos instrumentos ligados à tecnologia a que se encontram sujeitos diariamente e intensivamente ao longo da sua profissão, tendo em consideração a multiplicidade e complexidade de vectores em torno de uma negociação.

No seio dessa sociedade civil, a existência de discrepâncias agravadas pelo distanciamento entre a chamada geografia da informação e a concentração do poder económico / financeiro como por exemplo Londres, Nova Iorque, Tóquio, Paris, Hong Kong, São Paulo, Buenos Aires e México, derivado do volume de transaç̧ões diárias nestas praças financeiras, leva à combinação sob o aspecto de e-economy e e-diplomacy de redes para além fronteiras sem fusos horários no cruzamento de uma intersecção entre o sentido físico e digital da localização espácio-temporal.

Neste caso, podemos falar de uma subeconomia inserida via network structure, em que, de acordo com Guy Garron de la Carrière, a diplomacia se serve da economia e esta última se disponibiliza ao serviço da política externa (Carron de la Carrière, 1998). O governo serve-se arma económica na arena internacional, para 
atingir os seus fins, desde uma ajuda financeira ao embargo. Notemos que a diplomacia não substitui as relações empresariais e a agressividade do mercado financeiro. Em nosso entender, a diplomacia económica consiste na prossecução de uma política governamental na sua forma externa, condicionada a políticas predefinidas quer por instituições ao nível regional quer por actores, grupos de pressão empresariais ou não, inseridos num processo de mundialização (espaço único) e de globalização (proximidade e interdependência). Trata-se da transferência das questões económicas internas para a competência da diplomacia, por forma a garantir ao nível institucional um apoio de suma importância num determinado processo negocial quer de paz na resolução de um conflito internacional quer de cariz económico.

Assim sendo, a diplomacia varia consoante a evolução dos tempos, desde a Grécia Antiga a este início de terceiro milénio, utilizando métodos conforme as necessidades das políticas a defender e dos meios ao seu dispor. Esta diplomacia considerada por Abba Eban do próximo século, em nosso entender, coordena uma rede de informação e de informadores que se traduzem em encontros informais, podendo caber no intervalo de uma reunião na Comissão Europeia ou numa Assembleia Geral das Nações Unidas, por exemplo (Eban, 1998).

Além de todos estes aspectos, importa realçar o papel crescente da sociedade civil, enquanto novo actor das relações internacionais. Retomemos os 14 Pontos de Wilson, datados de 8 de Janeiro de 1918, que determinam o princípio democrático para as relações internacionais post-Primeira Guerra Mundial. O primeiro ponto revela-se de uma importância conspícua por abolir a diplomacia secreta, considerada fonte causal de guerra, como uma garantia na construção de um Estado democrático: "1..$^{\circ}$ Acordos de paz concluídos abertamente, após os quais não haverá mais acordos internacionais privados, seja qual for a sua natureza, mas a diplomacia procederá sempre franca e publicamente." Porém, o Presidente Wilson pretende conduzir e alargar o espectro interventor da diplomacia para o domínio público, ou seja, para a sociedade civil no domínio da participação da opinião pública.

Portanto, a passagem da diplomacia para a opinião pública, leia-se sociedade civil, deixa de ser algo de abstracto, de secreto, reservado a uma elite diplomática. Assim se compreende o crescente posicionamento nas mais diversas áreas de actuação desta sociedade civil, mas ainda longe de ser considerada um actor das relações internacionais, sobretudo no campo de actuação da diplomacia. Justamente, "A verdadeira política externa é a forma específica, à altura das suas forças, como cada estado se apresenta no mundo, perante as outras potências, em condições de jogar os seus recursos, de modo a manter a independência que o mesmo é dizer a capacidade colectiva." (Macedo, 1987: 8). 


\section{DA QUESTÃO COMUNICACIONAL}

Passaram 70 anos desde que Ortega y Gasset denunciara que a nossa sociedade, a vida pública, se havia entregue a uma única força espiritual que por definição também se ocuparia da actualidade: A Imprensa. Hoje, a Imprensa não é o único meio de comunicação a influir na sociedade: o vertiginoso poder da Televisão e a omnipresença da Internet acentuaram mais a dinâmica da "publicidade" que tanto preocupava o filósofo. A Sociedade de Informação coloca a função e o trabalho do jornalista e do comunicador no primeiro posto da relevância pública. Hoje mais se sabe, comparado com o denunciado por Ortega y Gasset, a responsabilidade social no exercício da profissão que é exigida ao jornalista e ao profissional de comunicação, uma ampla formação profissional e um excelente sentido ético.

A comunicação institucional é a única forma organizada de relação entre grupos, associações ou empresas e os demais grupos, indivíduos ou a opinião pública. Muitos são os centros de comunicação ou de assessoria de imprensa existentes. Tanto as empresas como os partidos políticos utilizam com muita frequência gabinetes de comunicação institucional. É a palavra que torna específico o seu humano. A palavra desdobra-se em três registos constitutivos essenciais: expressão, informação e convicção. São os jornalistas o elo de transmissão da mensagem. São eles que procedem à ligação entre o acontecimento e o conhecimento dos factos pelos destinatários. O importante é, pois, fazer passar através de um canal, o máximo de informação com o mínimo de distorção e com a máxima economia de tempo e de energia.

Os jornalistas podem também, com interesses formados ou por falta de formação e/ou conhecimentos, inadvertidamente, veicular informações pouco verdadeiras, manipular ou desinformar os seus leitores. A manipulação baseia-se numa estratégia central e, por vezes, única: a redução mais completa possível do auditório para discutir ou resistir ao que lhe é proposto. Aquilo que especifica a manipulação não é tanto o facto de haver uma estratégia, um cálculo, mas a sua dissimulação aos olhos do público.

No início do século XX, por muitos apelidados como "o século do convencer", é caracterizado por um desenvolvimento das técnicas manipulatórias e por uma sistémica confusão das fronteiras da palavra. A partir de 1914, formaram-se os primeiros especialistas com o objectivo de afinar técnicas de persuasão a usar quando não funcionam os meios habituais e razoáveis da ordem da discussão. Essas técnicas de manipulação da opinião pública passaram rapidamente a ser conhecidas pelos nomes de "propaganda" e "desinformação".

A palavra "desinformação" sofreu, desde há anos a esta parte, uma modificação no seu uso e no seu significado. O hábito corrente atribui hoje em dia à desinformação o sentido de informação incorrecta ou truncada, que pode ser utilizada de forma inadvertida ou voluntariamente para ocultar factos. Com efeito, a 
desinformação é uma acção que consiste em levar um receptor, que se pretende enganar, a tomar por válida certa descrição da realidade, favorável ao emissor, fazendo-a passar por informação segura e verificada. A comunicação estratégica serve para orientar o poder da comunicação e, assim, determinar o sentido e os resultados da acção para empreendermos com a finalidade de alcançarmos os nossos objectivos. Na opinião do investigador de comunicação Pere-Oriol Costa a expressão "comunicação estratégica" sublinha preocupações da esfera do comunicador e pressupõe que se determine que as comunicações são estratégicas. A expressão "estratégia da comunicação" remete para preocupações na área do estratega da organização e procura determinar que estratégias são comunicativas. A distinção entre comunicação estratégica e estratégia da comunicação é a mesma que entre uma acção estratégica e uma estratégia, ou seja, entre a parte (acções/decisões/tácticas) e o todo (a decisão marco que compreende uma série de decisões estratégicas).

\section{QUAL O SENTIDO DA DIPLOMACIA?}

Este novo sentido da diplomacia neste início de terceiro milénio consiste no redesenhar de um outro mapa post-11 de Setembro, baseado na conjugação de inúmeros vectores que se confundem actualmente com a esfera doméstica de cada Estado, enquanto entidade soberana, ou actor das relações internacionais.

Num sistema de complexidade crescente, a diplomacia acompanha o evoluir da percepção espácio-temporal da execução da política externa na prossecução da defesa do interesse nacional, como uma extensão do doméstico para a arena internacional, constituíndo ou não parceiros estratégicos que envolvam de pleno a sociedade civil e a componente da tecnológica na formação da network structure, em que se caminha para uma cyborgisation do estado e do indivíduo.

Se por um lado, a opinião pública pode destronar a elite política, por outro lado, a mesma detém uma força superior capaz de alterar o rumo das negociações, como por exemplo na esfera internacional Timor-Leste, Israel, Palestina e na área doméstica as manifestações públicas de desagrado quer na virtualidade (Internet) quer na rua como força impulsora, recordemos Paris. Além disso, a utilização quer do hard power quer do soft power pela superpotência norte-americana tem produzido um efeito dominó no sentido da procura de um equilíbrio mundial junto dos mais fracos, pela congregação de alianças estrategicamente pontuais, dotados de mecanismos cyberactivistas sejam eles de ordem religiosa, cultural, ideológica, social ou ambiental.

Por último, o Embaixador Alberto Franco Nogueira, ex-MNE, ao longo da sua obra escrita defende a imperatividade da manutenção de uma directriz firme, cuja capacidade é reveladora de isenção total a inferências político-ideológicas da definição à execução da política externa de um Estado, em nome da defesa do seu 
interesse nacional, mesmo em situação de crise permanente. Daí a importância vital de toda uma conjugação eficaz de uma escol imperativamente adaptada à evolução dos tempos e do acompanhamento das relações internacionais no "caminho para a unidade virtual do mundo de resistência assimétrica", tendencialmente globalizante na esfera económico-financeira, numa diversificação do campo de actuação do estado, levando a uma revisão da tipologia em torno do conceito de diplomacia e das suas derivações epistemológicas.

\section{NOTAS}

${ }^{1}$ EVERARD, J. (2000): Virtual States, The Internet and The Boundaries of the NationState, London, New York, Routledge. HARAWAY, D. (1991): Simians, Cyborgs, and Women: The Reinvention of Nature, London, Free Association Press; MOREIRA, A. (1969): "A Marcha para a Unidade do Mundo: Internacionalismo e Nacionalismo", en Separata de Estudos Políticos e Sociais, Vol. II, n. ${ }^{\circ}$ 4, Lisboa, ISCSPU.

2 NYE, J. (Fall 1990): "Soft Power", Foreign Policy, Washington D.C.: Carnegie Endowment for International Peace. N. . 80; NYE, J. S. (2002): The Paradox of American Power. Why the World's only Superpower can't go it alone, Oxford, Oxford University Press; MORGENTHAU, H. J. (1993): Politics Among Nations. The Struggle for Power and Peace, New York, McGraw-Hill.

${ }^{3}$ SANTOS, V. M. (2001): A Humanidade e o seu Património. Reflexões Contextuais sobre Conceptualidade Evolutiva e Dinâmica Operatória em Teoria das Relações Internacionais, Lisboa, ISCSP, Universidade Técnica de Lisboa.

${ }^{4}$ HUNTINGTON, S. (2001): O Choque das Civilizações e a Mudança na Ordem Mundial, Lisboa, Gradiva.

${ }^{5}$ Podemos ver, também, NICOLSON, H. (1988): Diplomacy, Washington, Institute for the Study of Diplomacy.

\section{BIBLIOGRAFIA}

ALBRIGHT, M. (2006): Os Poderosos e o Todo-Poderoso. Reflexões Sobre a América, Deus e o Mundo, Algés, Difel.

CARRON DE LA CARRIERE, G. (1998): La Diplomatie Économique. Le Diplomate et le Marché, Paris, Economica.

EBAN, A. (1998): Diplomacy for the Next Century, New Haven, Yale University Press.

EVERARD, J. (2000): Virtual States, The Internet and The Boundaries of the Nation-State, London and New York, Routledge.

GRAY, C. H. (2005): Peace, War, and Computers, New York, Routledge, 2005.

HARAWAY, D., (1991): Simians, Cyborgs, and Women: The Reinvention of Nature, London, Free Association Press.

HUNTINGTON, S. (2001): O Choque das Civilizações e a Mudança na Ordem Mundial, Lisboa, Gradiva.

MAGALHÃES, J. C. (1995): Diplomacia Pura, Bertrand Editora. 
MARCHUETA, M. R. (2002): O Conceito de Fronteira na Época da Mundialização, Lisboa, Cosmos Instituto da Defesa Nacional.

MCCAUGHEY, M. y AYERS, M. D. (2003): Cyberactivism. Online Activism in Theory and Practice, New York, Routledge.

MOREIRA, A. (1969): "A Marcha para a Unidade do Mundo: Internacionalismo e Nacionalismo”, en Separata de Estudos Politicos e Sociais, Vol. II, n. ${ }^{\circ}$ 4, Lisboa, ISCSPU.

MORGENTHAU, H. J. (1993): Politics Among Nations. The Struggle for Power and Peace, New York, McGraw-Hill.

NICOLSON, H. (1988): Diplomacy, Washington, Institute for the Study of Diplomacy.

NYE, J. (Fall 1990): "Soft Power", Foreign Policy, Washington D.C., Carnegie Endowment for International Peace, n. $^{\circ} 80$.

NYE, J. S. (2002): The Paradox of American Power. Why the World's only Superpower can't go it alone, Oxford, Oxford University Press.

SANTOS, V. M. (2001): A Humanidade e o seu Património. Reflexões Contextuais sobre Conceptualidade Evolutiva e Dinâmica Operatória em Teoria das Relações Internacionais, Lisboa, ISCSP, Universidade Técnica de Lisboa.

- (2002): Conhecimento e Mudança. Para uma Epistemologia da Globalização, Lisboa, ISCSP, Universidade Técnica de Lisboa.

- (Primavera 2006): "Global Civil Society. The Rise of a New Global Actor?", Nação E Defesa, Lisboa, Instituto da Defesa Nacional, n. ${ }^{\circ} 113$. 